NBER WORKING PAPER SERIES

\title{
BUSINESS CYCLES AND HOUSEHOLD FORMATION: THE MICRO VS THE MACRO LABOR ELASTICITY
}

\author{
Sebastian Dyrda \\ Greg Kaplan \\ José-Víctor Ríos-Rull \\ Working Paper 17880 \\ http://www.nber.org/papers/w17880
NATIONAL BUREAU OF ECONOMIC RESEARCH
1050 Massachusetts Avenue
Cambridge, MA 02138
March 2012

We thank seminar attendants at the ICREA-MOVE Conference on Family Economics and those at the EFACR small group of the NBER's Summer Institute. We thank Matthias Kredler for discussions. The views expressed herein are those of the authors and not necessarily those of the Federal Reserve Bank of Minneapolis, the Federal Reserve System, or the National Bureau of Economic Research.

At least one co-author has disclosed a financial relationship of potential relevance for this research. Further information is available online at http://www.nber.org/papers/w17880.ack

NBER working papers are circulated for discussion and comment purposes. They have not been peerreviewed or been subject to the review by the NBER Board of Directors that accompanies official NBER publications.

(C) 2012 by Sebastian Dyrda, Greg Kaplan, and José-Víctor Ríos-Rull. All rights reserved. Short sections of text, not to exceed two paragraphs, may be quoted without explicit permission provided that full credit, including $\odot$ notice, is given to the source. 
Business Cycles and Household Formation: The Micro vs the Macro Labor Elasticity

Sebastian Dyrda, Greg Kaplan, and José-Víctor Ríos-Rull

NBER Working Paper No. 17880

March 2012

JEL No. E32,J10,J22

\begin{abstract}
We provide new evidence on the the cyclical behavior of household size in the United States from 1979 to 2010. During economic downturns, people live in larger households. This is mostly, but not entirely, driven by young people moving into or delaying departure from the parental home. We assess the importance of these cyclical movements for aggregate labor supply by building a model of endogenous household formation within a real business cycle structure. We use the model to measure how much more volatile are hours due to two mechanisms: (i) the presence of a large group of mostly young individuals with non-traditional living arrangements; and (ii) the possibility for these individuals to change their living situation in response to aggregate conditions. Our exercise assumes that older people living in stable households have a Frisch elasticity that is consistent with the micro evidence that is based on such people. The inclusion of people living in unstable households yields an implied aggregate, or macro, Frisch elasticity that is around $45 \%$ larger than the assumed micro elasticity.
\end{abstract}

Sebastian Dyrda

University of Minnesota

Department of Economics

4-101 Hanson Hall

1925 Fourth Street South

Minneapolis, MN 55455

and Federal Reserve Bank of Minneapolis

dyrda020@umn.edu
José-Víctor Ríos-Rull

University of Minnesota

Department of Economics

4-101 Hanson Hall (off 4-179)

1925 Fourth Street South

Minneapolis, MN 55455

and NBER

vr0j@umn.edu

Greg Kaplan

Department of Economics

University of Pennsylvania

160 McNeil Building

3718 Locust Walk

Philadelphia, PA, 19104

P: +1 2158981875

gkaplan@sas.upenn.edu 


\section{Introduction}

Macroeconomists often argue that the Frisch elasticity of labor supply is larger than what microeconomists have measured (see Chetty, Guren, Manoli, and Weber (2011a) and Ljungqvist and Sargent (2011) for recent discussions). While microeconomists' arguments are based on measurements of this elasticity using data on the labor supply choices of actual people, the rationale for macroeconomists preferring a larger elasticity is less clear. Macroeconomists' arguments are implicitly based on the desire to account for aggregate movements in hours worked through movements in prices. A more explicit, or empirical, argument for preferring a larger elasticity is based on criticisms about the way that microeconomists have performed their measurements. These criticisms insist that the micro measurements miss margins that

are relevant for the behavior of an aggregate economy. Some of these criticisms (movements in the extensive margin, existence of more volatile secondary earners in the family, explicit consideration of lifetime labor supply) have been accounted for by microeconomists in recent work and have contributed to increase the microeconomic assessment of the labor elasticity. However, the gap between the two views remains large. Macroeconomists (e.g.,Prescott (2006)) sometimes insist that the elasticity of the stand-in household can be larger than that of any real household.

In this paper we provide a measurement of an aggregate, or macro, elasticity that is consistent with micro estimates, yet yields a much higher value. The rationale is that because of the nature of available micro data, micro estimates of the Frisch elasticity tend to be based on the behavior of people who live in what we call stable households: people whose living arrangements do not change much over time. In practice, this usually translates into a focus on married people or people above a certain age. However, the labor force consists of many other types of people who live in less stable households. Such people, including the young and the single, frequently change whom they live with: sometimes alone, sometimes with a partner, often with their parents. These movements are in part a response to changes in individual and aggregate labor market conditions.

The first contribution of our paper is to provide new evidence on aggregate business cycle movements in the living arrangements and labor supply of these less stable individuals. Using quarterly data from the Current Population Survey (CPS), we document large cyclical fluctuations in the average size of US households. During economic expansions households shrink, while during recessions households expand. To quantify the overall importance of 
these movements, we construct a new series for aggregate hours per household and compare it to traditional measures of hours per person. We find that hours per person are around $15 \%$ more volatile than hours per household, with the difference due to the variation in household size. A substantial fraction of this variation is due to the part of the population that we term unstable: people whose household structure is most likely to vary over the business cycle. We identify groups of people that move in and out of households frequently, and use these to partition the population into those that live in stable households and those that do not. Our analysis considers three such groups: people under 30; people that have never been married; and people that are both under 30 and have never been married. In addition to having a large volatility in household size, we show that these people work more hours when living alone than when living with other more stable people, and have a higher volatility of hours worked no matter what type of households they live in. ${ }^{1}$

For at least two reasons, it is important to recognize that living arrangements change with the business cycle, and to incorporate these movements into macro models. First, despite labor market inputs being measured at the level of the individual, consumption is almost always measured at the level of a household. This reflects the fact that for the majority of the population, spending decisions are made in the context of shared living arrangements, which in turn reflects the presence of economies of scale within households. Thus, for any analysis of the welfare costs of business cycles (and the welfare implications of policies that affect the cycle), the distinction between individuals and households is potentially important. This is true because, as we document, the relationship between persons and households itself features significant business cycle variation. Yet, there are almost no quantitative business cycle models that make this distinction. Second, a growing literature has recognized that the labor supply decisions of individuals also reflect the opportunities and preferences of the people they live with. Hence, changes in living arrangements can be important for labor market variables even at the individual level.

Our second contribution in this paper is to explicitly incorporate the behavior of individuals with flexible living arrangements into the calculation of a macro labor elasticity. To do this, we build and calibrate a real business cycle model with stable and unstable people (which we also refer to as old and young, respectively), where the unstable optimally choose whether to move and live with a stable person or to live alone. We restrict stable people to have the labor

\footnotetext{
${ }^{1}$ We define an unstable person to be living alone if they do not live in the household of a corresponding stable person. For example, this means that a young person living with other young people as roommates is considered as living alone.
} 
elasticity measured by microeconomists. We then examine the volatility of total hours in the model and recover the implicit labor elasticity that a standard representative agent model with only stable people would need, in order to replicate this volatility of hours worked. We find that the required Frisch elasticity of the stand-in household is around $40 \%-50 \%$ higher than the micro estimates.

The most important feature of our calibration procedure is that we not only target the relevant first moments of the economy, but we also target the hours volatility of the unstable living alone, the hours volatility of the unstable living in stable households, and the volatility of the fraction of unstable people living alone, all relative to the volatility of the hours worked by stable households. It is crucial to understand the importance of targeting these volatilities relative to the hours volatility of the stable group, rather than targeting their absolute magnitudes. The reason is that we do not want to allow total factor productivity (TFP) shocks, which are the source of fluctuations in our model, to account for any more of the variance of hours of the unstable than they do for the hours of the stable. In our calibrated model, the fraction of the variance of total hours accounted for by TFP shocks is equal for (i) hours worked by stable households, (ii) hours worked by unstable people living alone, (iii) hours worked by unstable people living together with stable people, and (iv) the fraction of unstable people living in stable households. By calibrating the model in this way, we ensure that the volatility of total hours is not larger than in standard representative agent models, purely because of a large volatility of hours of the unstable.

In our model, there are three reasons why the volatility of hours worked is higher than in a representative agent economy with the same Frisch elasticity for stable people. First, as in the data, unstable individuals have a higher volatility of hours than stable individuals, regardless of whether they live in stable or unstable households. Second, the existence of a second group of workers with higher hours volatility generates movements in the relative prices of capital and labor in equilibrium - wages are less volatile and rates of return are more volatile. These price movements induce stable individuals to have a higher volatility of hours than what they would have in the representative agent world because their hours respond more to increases in interest rates than to reductions in wages. Third, during expansions, the unstable tend to move out of stable people's households into their own households (or together with other unstable people, which we consider as living alone). Since they work more hours when living alone, this increases aggregate hours volatility.

Clark and Summers (1981) first noted that labor volatility is high for young workers. Kydland 
(1984), Ríos-Rull (1992), Ríos-Rull (1993), Ríos-Rull (1996), and Gomme, Rogerson, Rupert, and Wright (2005) also documented differences in labor volatility by age or skill groups. They posed models with age or skill variation to explore the business cycle implications of these economies and the possible source of the variation in volatility. More recently, Jaimovich and Siu (2009) exploited the higher volatility of the young to argue that the Great Moderation (the reduction in economic volatility between 1984 and 2007) was due in part (between onefifth and one-third) to demographic change that reduced the share of young people in the G7 economies. These papers, and, to our knowledge, all existing studies of the business cycle, assume that household size is constant. ${ }^{2}$

Jaimovich, Pruitt, and Siu (2009) explore the role of imperfect substitution in production between young and old workers to account for the higher volatility of the young. They cleverly argue that the relative volatility of wages between young and old workers points to an explanation based on differences in technology rather than preferences. In our paper, the focus is not on explaining the labor market volatility of young workers, but on the interaction between their living arrangements and hours fluctuations. Despite the arguments in Jaimovich, Pruitt, and Siu (2009), we choose to generate age differences in hours volatility through differences in preferences rather than technology. This choice is not crucial to our analysis, yet we prefer it because had we used differences in technology, the specific cross derivatives that would be required in the production function would exacerbate some of the price effects that we discuss in Section 6. We want to isolate what most researchers would consider the effects of coresidence within the standard model.

Kaplan (2010) also studies the relationship between the labor market and the tendency for the young to move in with the old in response to labor market outcomes. He estimates a dynamic game between youths and their parents to understand the structural microeconomic relationship between changes in living arrangements and labor supply. In this paper we model this interaction in a much simpler way, in order to be able to build a model that is amenable to equilibrium business cycle analysis with aggregate technology shocks.

The paper proceeds as follows. Section 2 documents business cycle properties of household composition and labor market variables. Section 3 defines the question that we address in our quantitative exercise. Section 4 describes a model with two types of agents, old and young, with the latter moving in and out of the formers' households. Section 5 discusses how we

\footnotetext{
${ }^{2}$ There are, of course, many papers about household formation, outside of a business cycle context.
} 
calibrate the model, giving special attention to the issue of the relative variances of hours of the old and the young. Our findings for the baseline economy are discussed in Section 6, together with the properties of model economies with different calibration strategies. Section 7 studies a representative agent representation of our model economies that provide what we call the macro elasticity. Section 8 concludes.

\section{Empirical Evidence}

In this section we document several new facts about changes in household composition over the business cycle. We provide evidence to support the following facts:

1. There are large fluctuations in average household size over the business cycle: during economic downturns, people live in large households. A substantial part of these fluctuations are due to young or unmarried individuals moving in and out of the households of older and married individuals.

2. Household formation offsets a substantial fraction of the volatility in individual hours over the business cycle: the cyclical variance of hours per household is around $15 \%$ lower than corresponding variance of hours per person.

3. Those individuals who are most likely to change households are the same individuals with the most volatile labor market outcomes over the business cycle.

\subsection{Data}

Data source Our primary source of data is the Basic Monthly Surveys from the Current Population Survey (CPS). Because it contains data on labor market outcomes of all individuals in a given household, the CPS is an ideal data set for measuring aggregate movements in household composition at business cycle frequencies. We have monthly data on a large cross section of individuals from 1979 to 2010, which we use to construct deseasonalized quarterly series from 1979:Q1 to 2010:Q3.

Household definition Our definition of a household mirrors that of the CPS: all persons who occupy a dwelling unit. A dwelling unit is defined as a room or group of rooms intended for occupation as separate living quarters and having either a separate entrance or complete 
cooking facilities for the exclusive use of occupants. We choose this definition both because it is simple to compute given the available data, and because to a large extent it coincides with the notion of a household from the point of view of economic theory. In our model, the defining feature of a household is that it contains a set of people who benefit from economies of scale in consumption.

Measurement issues The benefits of the monthly CPS are its large size and high frequency, while its main drawback is that it is cross-sectional data. This means that we cannot discuss a notion of who moves in with whom when household composition changes. We can only observe the other people that an individual is living with, not the physical structure that he or she is living in. To know who physically does the moving, we would need panel data.

Although measuring household composition is essentially an exercise in counting numbers of people and numbers of households that satisfy various criteria, some complications arise. First, there have been significant low-frequency secular trends in the age and demographic structure of the population over the period that the data covers. In particular, the aging of the baby boomer generation has led to a systematic change in household composition and average household size because of life cycle effects in living arrangements. We detrend our data series using a Hodrick-Prescott (HP) filter. This effectively removes the systematic changes induced by changes in the demographic structure of the population.

Second, the sampling structure of the CPS complicates matters. The CPS is a non-random sample of dwellings. In each sampled dwelling, information is gathered about all people who currently reside there. This generates a non-random sample of individuals. One of these individuals is labeled as the household head. In order to calculate statistics that are representative of the US population as a whole, the CPS constructs weights based on observable features of individuals (non-interview status, age, sex, race, and Hispanic origin). Households are counted by constructing weighted counts of household heads, while individuals are counted by constructing weighted counts of all household members. Weights are calculated using data from the decennial census and are updated between census dates using population projections. This updating of census weights can sometimes lead to discrete jumps in the relative counts of people of different types. Since there are systematic differences in the average household structure of individuals with different characteristics, such changes in the weights may lead to discrete changes in our measures of household structure. The most important of these changes occurred with the updating of the weights in January 1991. To deal with the updating in the 
CPS weights, we allow for a structural break by filtering the data separately before and after 1990.

\subsection{Cyclicality in Household Composition}

Household Size in Adult Population We start by examining average household size in the population aged 18 and over. Average household size is defined as the total number of households divided by the total number of persons in this age range. The solid blue line in Figure 1a plots the raw time series for household size. On the same plot, the dashed red line shows average hours worked per person aged 18 and over, as a measure of aggregate conditions. The plots show a clear negative correlation between the two series. Overall, this correlation is -0.75 . The correlation between household size and hours is exacerbated at business cycle frequencies: there is a sharp increase in the number of people per household in the 1981 and 2008 recessions, and a smaller increase in the milder recessions of 1990 and 2001. In Figure 1b we plot the corresponding HP-filtered series. The plot shows a significant negative correlation that is also exacerbated during the two large recessions $(-0.33)$.

To put the size of these changes in household size into perspective, during the most recent recession, the seasonally adjusted number of persons per household aged 18 and over increased from 1.883 in 2007:Q3 to 1.925 in 2010:Q4. This 2.2\% rise in persons per household corresponds to roughly 2.5 million households taking in an extra person during this recession. ${ }^{3}$ This evidence thus suggests large aggregate movements in a variable that is assumed constant in almost all existing studies of business cycles.

Household Size for Different Subgroups In Figure 2 we plot average household size for individuals in different subgroups. We consider two alternative ways to divide the population. First we compare young individuals to old individuals. The raw data in Figure $2 \mathrm{a}$ and the filtered data in Figure $2 \mathrm{~b}$ both show that the household sizes of 18 to 30 year olds are more cyclical than those of 31 to 65 year olds, although the older group still features substantial variation in household size over the business cycle. We also compare never-married individuals with those who have been married at least once. The plots show similar findings: nevermarried individuals have more volatile and cyclical household sizes. It is well known in the literature that these two groups (the young and the single) also have much higher than average

\footnotetext{
${ }^{3}$ Calculation based on assumption of 116, 783, 000 households in 2008 from census table HH1, available at http://www. census.gov/population/www/socdemo/hh-fam.html.
} 


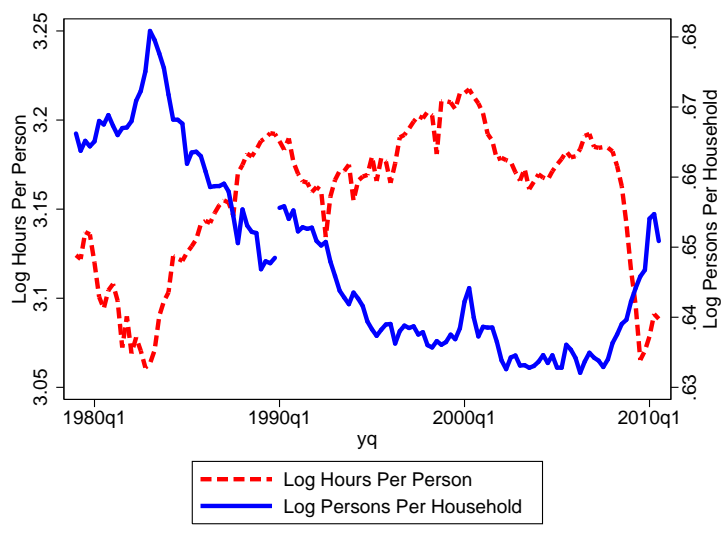

(a) Raw time series

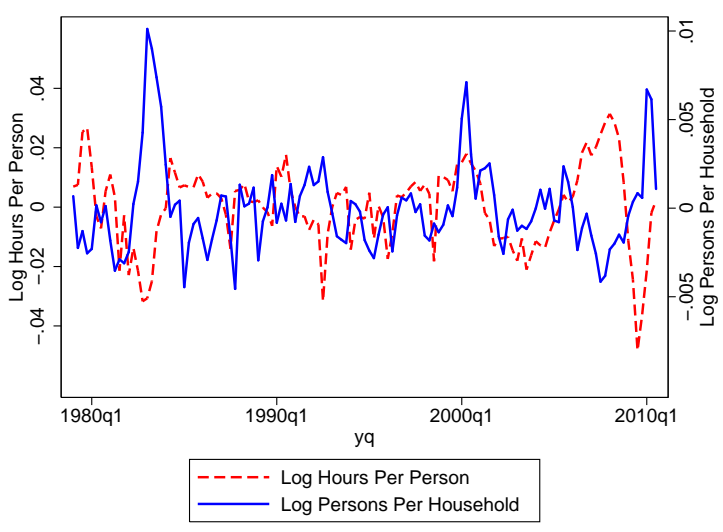

(b) HP-filtered series

Figure 1: Persons per household, hours per person

Notes: All people 18 years and over. Households with no people aged 18 years and over included. Quarterly data, 1979:Q1-2010:Q3, authors' calculations from Basic Monthly CPS. Deseasonalized. HP-filtered before and after 1990 separately with parameter 1600.

Table 1: Cyclical Volatility of Persons Per Household

\begin{tabular}{lccc}
\hline \hline & $\sigma(\log$ hh size $)(\%)$ & $\sigma(\log$ hours $)(\%)$ & Ratio \\
\hline $18-65$ & 0.36 & 1.42 & 0.25 \\
$18-30$ & 0.52 & 2.01 & 0.26 \\
$31-65$ & 0.28 & 1.23 & 0.23 \\
\hline Never married & 0.60 & 2.06 & 0.29 \\
Married & 0.28 & 1.25 & 0.22 \\
\hline \hline
\end{tabular}

labor market volatility (Kydland (1984), Ríos-Rull (1996), Gomme, Rogerson, Rupert, and Wright (2005), Jaimovich and Siu (2009)). This turns out to be a general feature of the data on cyclicality in household size: those individuals with more business cycle volatility in labor market variables also have larger movements in household size over the business cycle. To illustrate this point more concretely, Table 1 reports the standard deviation of HP-filtered log household size and log hours for all individuals aged 18 to 65 and for the two subgroupings based on age and marital status.

Parental Coresidence Figure 3 shows evidence on the cyclicality of coresidence between parents and children. We measure the parental coresidence rate for individuals aged 18 to 30 as the fraction of this age group whose relationship to the household head is that of a child. This is the same definition that is adopted by the Census Bureau. Figure 3a shows a large 


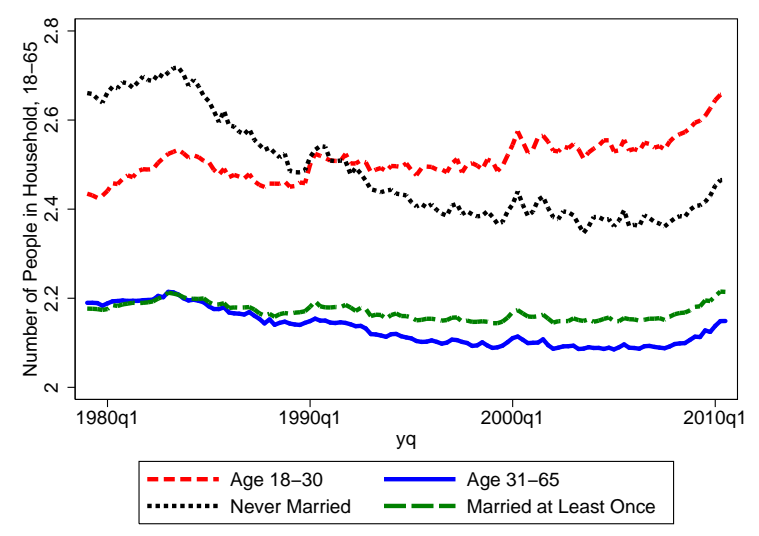

(a) Raw time series

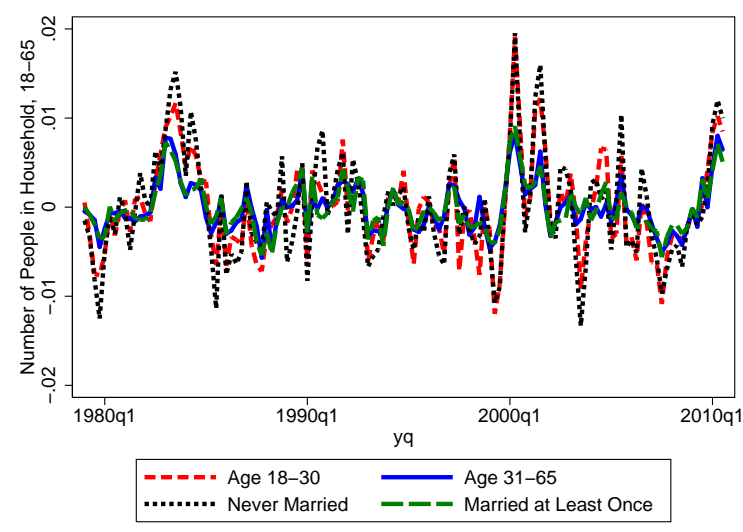

(b) HP-filtered series

Figure 2: Household size by subgroup

Notes: All people aged 18-65. Household size reflects average number of people aged 18-65 living in same household as individual in subgroup. Quarterly data, 1979:Q1-2010:Q3, authors' calculations from Basic Monthly CPS. Deseasonalized. HP-filtered before and after 1990 separately with parameter 1600.

increase in parental coresidence around the 1981 and 2008 recessions. Figure 3b shows that at business cycle frequencies there is again a strong negative correlation between the rate of parental coresidence and hours worked by 18 to 30 year olds. One reason that it is informative to examine parental coresidence as opposed to household size more broadly is that whereas in general we do not know who moves in with whom, changes in coresidence rates among 18 to 30 year olds are reasonably likely to have been driven by children moving in with parents, rather than vice versa.

\subsection{Labor Market Variables and Changes in Household Size}

Hours Per Household Almost all analyses of business cycle fluctuations in labor market variables are based on individual-level data: either hours or employment per person. However, for many economic questions the household is a more relevant unit of analysis, for two reasons. First, consumption, and hence welfare, are both decided and measured at the household level. Second, labor supply decisions are often jointly made within the household. To assess the importance of distinguishing between labor market fluctuations at the household and individual levels, we begin by constructing series for employment and hours per household. These series are also important in their own right, since they are useful for understanding the role of endogenous household formation for mitigating the welfare costs of business cycle-driven 


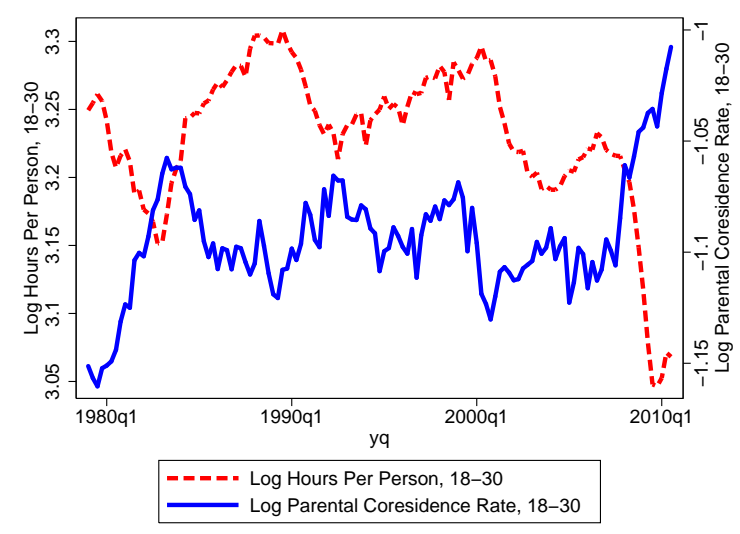

(a) Raw time series

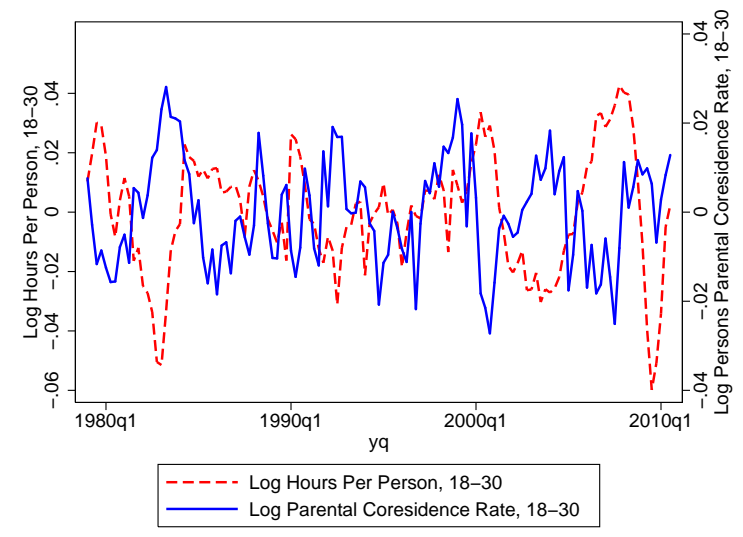

(b) HP-filtered series

Figure 3: Parental coresidence, hours per person

Notes: All people aged 18-30. Quarterly data, 1979:Q1-2010:Q3, authors' calculations from Basic Monthly CPS. Deseasonalized. HP-filtered before and after 1990 separately with parameter 1600.

labor market outcomes. ${ }^{4}$ Figure 4 plots the cyclical component of hours and employment per person and per household from 1979 to 2010.

A Useful decomposition: hours per household vs. households per person To quantify how important are changes in household size for offsetting hours and employment movements at business cycle frequencies, we consider the following decomposition. Let hours be denoted by $H$, employed person by $E$, households by $F$, and persons by $N$. Then we can decompose total hours per person as

$$
\frac{H}{N}=\frac{H}{F} \times \frac{F}{N}
$$

This decomposition says that we can write hours per person as hours per household multiplied by households per person. Similarly, we can decompose total employment per person as

$$
\frac{E}{N}=\frac{E}{F} \times \frac{F}{N}
$$

\footnotetext{
${ }^{4}$ Mulligan and Rubinstein (2003), in an unpublished paper, document some statistics similar to ours. However, there are some important differences: (i) their data do not cover the most recent recession; (ii) they focus on annual data, so have only around 30 data points; and (c) they do not analyze these series for relevant subgroups in the population.
} 


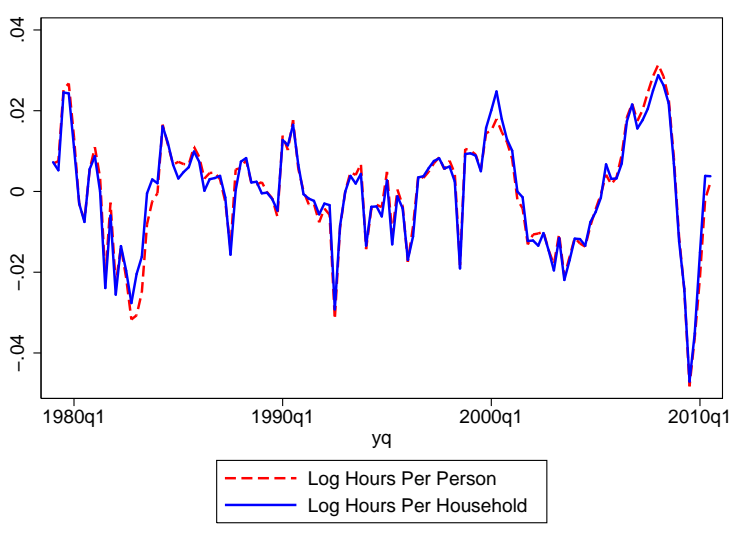

(a) Hours

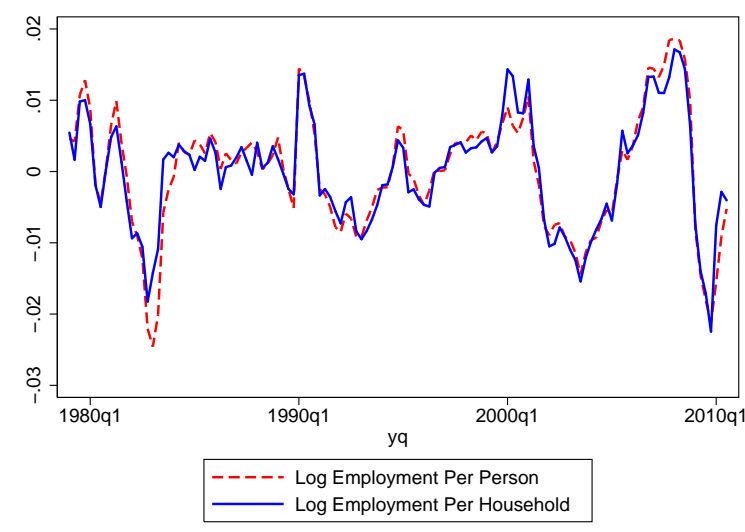

(b) Employment

Figure 4: Household-level vs. individual-level HP-filtered labor market variables Notes: All people aged 18 and over. Quarterly data, 1979:Q1-2010:Q3, authors' calculations from Basic Monthly CPS. Deseasonalized. HP-Filtered before and after 1990 separately with parameter 1600.

Taking logs and variances yields

$$
V\left(\log \frac{H}{N}\right)=V\left(\log \frac{H}{F}\right)+V\left(\log \frac{F}{N}\right)+2 C O V\left(\log \frac{H}{F}, \log \frac{F}{N}\right) .
$$

Table 2 reports the result of this decomposition for employment and hours, using HP-filtered data at annual and quarterly frequencies. The results suggest that between $13 \%$ and $19 \%$ of fluctuations in per person labor market variables over the business cycle are offset at the household level by endogenous changes in household structure. These findings imply that the margin of endogenous household formation may be quantitatively important for understanding both labor market fluctuations and how households respond to changes in aggregate conditions. Table 2 also reports analogous calculations when the data are detrended using a linear trend rather than an HP-filter. Detrending the data in this way yields an even larger contribution of movements in the number of persons per household. Since the difference between the two methods of detrending is the effect of medium-frequency secular changes due to episodes such as the productivity slowdown during the 1990's, these results imply that the mechanisms we are highlighting in this paper may be important for understanding labor movements over longer frequencies in addition to business cycles. 
Table 2: Decomposition of hours and employment per person

\begin{tabular}{lcccc}
\hline \hline & \multicolumn{2}{c}{ Quarterly Data } & \multicolumn{2}{c}{ Annual Data } \\
& $\begin{array}{c}\text { HP-filter } \\
(\%)\end{array}$ & $\begin{array}{c}\text { Linear trend } \\
(\%)\end{array}$ & $\begin{array}{c}\text { HP-filter } \\
(\%)\end{array}$ & $\begin{array}{c}\text { Linear trend } \\
(\%)\end{array}$ \\
\hline $\begin{array}{l}\text { Hours: } V\left(\log \frac{H}{N}\right) \\
\text { Households per person }+ \text { covariance }\end{array}$ & 15.2 & 25.5 & 13.7 & 21.7 \\
\hline $\begin{array}{l}\text { Employment: } V\left(\log \frac{E}{N}\right) \\
\text { Households per person }+ \text { covariance }\end{array}$ & 16.4 & 39.5 & 19.0 & 28.9 \\
\hline \hline
\end{tabular}

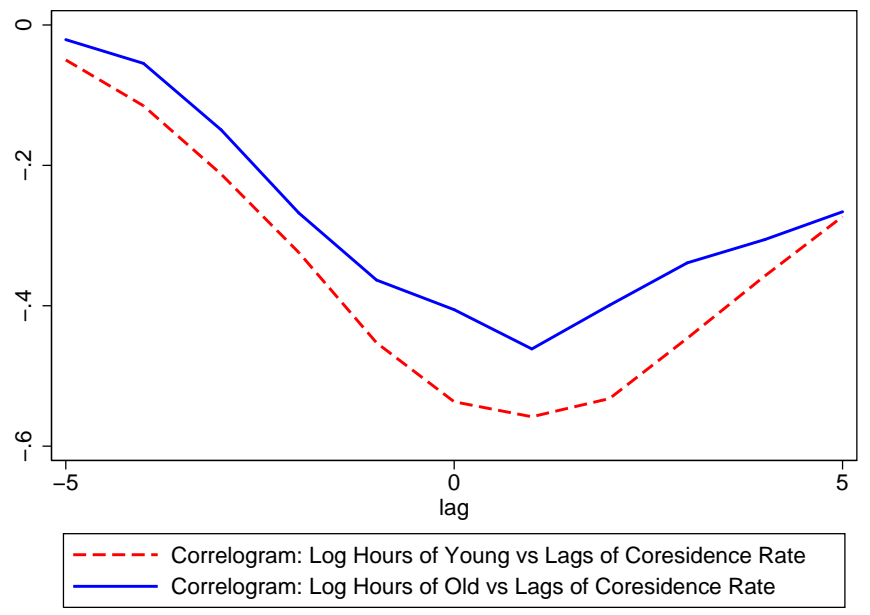

Figure 5: Correlogram: Log hours of young and old vs. lags of coresidence rate Notes: Quarterly data, 1979:Q1-2010:Q3, authors' calculations from Basic Monthly CPS. Deseasonalized. HP-filtered before and after 1990 separately with parameter 1600. Definition of young and old is based on calibration described in Section 5 .

Cross-correlations Figure 5 illustrates the joint business cycle dynamics of living arrangements and hours worked in the form of a cross-correlogram. We highlight the following two features of this figure that motivate some of our modeling choices. First, note that the negative correlation is very long lived. Second, note that hours worked of both the young and the old slightly lag the fraction of the young living with the old: the lowest value of the correlation is one period behind.

\section{The Question}

Given the preceding empirical analysis, it is tempting to conclude that in a model with a representative household, one should be concerned with the variance of hours per household 
rather than the variance of hours per person, and to stop there. However, we would like to go further. Our goal is to jointly account for movements in hours and household size, and to understand their implications for the aggregate, or macro, labor elasticity. Specifically, we take the following steps:

1. We build a model that is suitable for the study of business cycles (a stochastic growth model with choice of hours), where there are two types of agents and a margin for adjusting household composition. Unstable agents (whom we will interpret as young or single) have the option to move in and out of the households of stable agents (which we loosely interpret as the households formed by their relatives).

2. We map this model to data in order to ask how large are the fluctuations in total hours induced by productivity shocks when agents satisfy their intratemporal first-order condition for labor supply. To do this, we impose that the ratio of the variance of hours of the old workers in the model to that in the data is the same as the ratio of the variance of hours of the young workers in the model to that in the data, and is also the same as the ratio of the variance of household size in the model to that in the data. By matching relative variances in this way, we ensure that we do not impute to productivity shocks a larger role in shaping household size and hours of the young than is imputed to hours of the old.

3. We use the model to compute the macro Frisch elasticity that is consistent with a micro elasticity that is estimated from data that include only individuals in stable households. In our baseline calibration we will take this Frisch elasticity to be 0.72 , but our results do not hinge on any particular value for this micro elasticity. We ask what elasticity does a standard representative agent model need in order to generate the same variance of hours as in our model, when stable agents have a Frisch elasticity given by the micro estimate.

4. We decompose the difference between the micro elasticity and our implied macro elasticity into three components: (i) the direct effect of the presence of the highly volatile unstable agents; (ii) endogenous movements in household composition through choices made by the unstable agents; and (iii) the indirect effect that arises because the unstable agents affect cyclical movements in relative prices. 


\section{Model}

Demographics Our model is populated by two types of agents. We label one type as stable, as a stand-in for old, independent, or married; and the other type as unstable, as a stand-in for young, dependent, or unmarried. For consistency with our baseline calibration, we will refer to the two types as old and young in our description of the model. The fundamental difference between the two types of agents is that the old always live in their own stable households, whereas the young live in unstable households in the sense that they sometimes join other people to form multiperson households and sometimes they do not.

Old agents in our model, like the agents in standard models, have preferences over consumption and leisure in the current and all future periods and, consequently, make savings and work decisions. In addition, the old are associated to some young agents whose company they enjoy, in a separable and unmodeled way, but over whom they have no altruistic feelings. In this fashion, if a young agent chooses to join the old household, she is welcomed in, and she shares part of the consumption of the old due to the presence of economies of scale within the household. The arrival of the young occurs after the old have chosen how much to work and save. We explicitly model the fact that the old and the young have different amounts of efficiency units of labor and that the young and the old have different preferences over pairs of consumption and leisure within the period. Further, for convenience, we assume that the young are extremely impatient.

Young agents generally prefer to live alone, although the strength of this preference is a random variable that varies from period to period: young agents receive an idiosyncratic draw of how much they dislike to live with the old. In some circumstances (low wages, good draws), young agents will choose to join an old household. In an ironic abuse of language, we assume that both the young and the old never age. ${ }^{5}$ We build this structure on top of a standard growth model that is suitable for quantitative macroeconomic analysis.

The old There is a measure $\mu$ of old agents that live in stable households of size $\gamma$. Consequently, there are $\frac{\mu}{\gamma}$ of these households. They can be invaded by a young agent, but only after having made their choice of consumption and hours worked. Consequently, old agents must assess the probability that this happens. Let $x$ denote the probability that (or fraction of)

\footnotetext{
${ }^{5}$ It is easy, but tedious, to show that this model is isomorphic to another model where agents do age and the young inherit the assets of the old.
} 
young agents that choose to join an old household. Given the relative sizes of the population groups, the per-period utility function is given by

$$
\begin{aligned}
& u\left(c^{o}, h^{o}, x\right)=\left[1-\frac{x(1-\mu) \gamma}{\mu}\right]\left[\log \frac{c^{o}}{\zeta^{o o}}-\psi^{o} \frac{\left(h^{o}\right)^{1+\frac{1}{\nu^{o}}}}{1+\frac{1}{\nu^{o}}}\right] \\
& +\frac{x(1-\mu) \gamma}{\mu}\left[\log \left(\frac{c^{o}}{\zeta^{o o}+\zeta^{o}}\right)-\psi^{o} \frac{\left(h^{o}\right)^{1+\frac{1}{\nu^{o}}}}{1+\frac{1}{\nu^{o}}}\right],
\end{aligned}
$$

where the first term alludes to being alone and the second term to having been invaded by a young agent. Here $\zeta^{o o}$ indicates the economies of scale among the old: if $c^{o}$ is spent by a household of size $\gamma$, then $\frac{c^{o}}{\zeta^{o o}}$ is enjoyed on a per capita basis. Similarly, parameters $\left\{\psi^{o}, \nu^{o}\right\}$ take into account the disutility on a per capita basis of having household members work a total amount of $h^{o}$ hours per period. Notice that given the functional form, $\nu^{o}$ is the Frisch elasticity of labor. The additional parameter $\zeta^{o}$ reflects the strain imposed by the young. The old discount the future at rate $\beta$ and face the following period budget constraint:

$$
c^{o}+a^{\prime}=w h^{o}+(1+r) a,
$$

where $a$ are the assets held by the household, $w$ and $r$ are factor prices, and where we have normalized the efficiency units of labor of the old to 1 .

The young There is a measure $1-\mu$ of young agents. These agents have preferences over consumption, leisure, and the type of household they live in, but are completely impatient (hand-to-mouth). Every period they draw an i.i.d. idiosyncratic shock, $\eta \sim F(\eta ; \lambda)$, to the disutility of sharing a household with an old agent. They can join (invade) a stable household after observing all relevant information within the period: the realization of $\eta$, and the aggregate state of the economy that determines prices and allows them to forecast the relevant decisions of the old. If the agent lives alone, denoted $A$, its utility is

$$
u\left(c^{y A}, h^{y A}\right)=\frac{\left(c^{y A}\right)^{1-\sigma}}{1-\sigma}-\psi^{y} \frac{\left(h^{y A}\right)^{1+\frac{1}{\nu^{y}}}}{1+\frac{1}{\nu^{y}}} .
$$

Notice that while the utility of the old displays log consumption, the young agents have a different curvature. Since the young do not care about the future, log utility would result in 
constant hours, and a different shape of the utility function is required so that hours of the young vary over the cycle.

When a young agent lives together with an old household, denoted $T$, its utility is given by

$$
u\left(c^{y T}, h^{y T}, \eta\right)=\frac{\left(c^{y T}+\zeta^{y}\right)^{1-\sigma}}{1-\sigma}-\psi^{y} \frac{\left(h^{y T}\right)^{1+\frac{1}{\nu^{y}}}}{1+\frac{1}{\nu^{y}}}-\eta+\left[\left(1+\Delta x_{S S}\right)^{\gamma_{2}}-1\right]
$$

Here $\zeta^{y}$ reflects the economies of scale in the old household, or, in effect, how much free riding the young get from the old. Note that these economies of scale do not depend on the consumption of the old directly. The reason is that consumption of the old lags the cycle, and if it affected the location decision directly, it would introduce dynamics on the behavior of the fraction of the young living with the old at odds with the features of the data described by Figure 5 .

The final term in the utility function reflects an externality in living arrangements. It requires both an explanation and a justification. $\Delta x_{S S}$ is the deviation of $x_{t-1}$, the fraction of the young living with the old in the previous period, from its steady-state value. When $x$ is relatively large, there are more young people living with old people, and the disutility from living with one's older relatives is smaller. We have in mind the idea that part of the disutility of living with one's parents is due to a social stigma against living with parents that is smaller when there are more young people doing it. In the steady state this effect is normalized to zero. The externality, particularly in the lagged form that we postulate, plays an important role in generating dynamics for living arrangements that are consistent with the cross correlation between hours worked by the young and the fraction of the young living with the old reported in Section 2.3. We discuss this issue further in Section 5.

The young living alone choose $\left\{c^{y A}, h^{y A}\right\}$ while the young living together choose $\left\{c^{y T}, h^{y T}\right\}$. Both choices satisfy the budget constraint of the young:

$$
c^{y j}=\epsilon^{y} w h^{y j}, \quad j \in\{A, T\}
$$

where $\epsilon^{y}<1$ is the efficiency units of the young relative to the old. 
Production This structure is integrated onto a standard growth model. There is an aggregate production function

$$
Y=z K^{\alpha} N^{1-\alpha}
$$

and the resource constraint for the economy is

$$
C+\left[K^{\prime}-(1-\delta K)\right]=Y,
$$

where $C$ is aggregate consumption, $K$ is aggregate capital, $Y$ is output, $N$ is the aggregate labor input (not total hours worked), and $z$ is an $\operatorname{AR}(1)$ productivity shock.

Aggregation Despite the fact that our model features multiple types of agents and households, aggregation in this environment is relatively simple. There are three types of choices: those made by the old, by the young alone, and by the young together (recall that the old cannot make their choices contingent on whether a young agent is present). There are three types of households: old households without young agents (a measure $\frac{\mu}{\gamma}-x(1-\mu)$ ), old households with young agents (a measure $x(1-\mu)$ of those), and young agents alone (with measure $(1-x)(1-\mu))^{6}$

The aggregate values for consumption $(C)$, labor input $(N)$, and hours $(H)$, are given by

$$
\begin{aligned}
& C=\frac{\mu}{\gamma} c^{o}+(1-\mu) \quad\left[x c^{y T}+(1-x) c^{y A}\right], \\
& N=\frac{\mu}{\gamma} h^{o}+(1-\mu) \epsilon^{y}\left[x h^{y T}+(1-x) h^{y A}\right], \\
& H=\frac{\mu}{\gamma} h^{o}+(1-\mu) \quad\left[x h^{y T}+(1-x) h^{y A}\right],
\end{aligned}
$$

Capital is owned by the old, so wealth is equal to total capital: $K=a \frac{\mu}{\gamma}$.

Equilibrium Our model is simple enough such that the objects required to define an equilibrium are the same as in a standard representative agent model. The aggregate state of the economy is $s=\left\{z, K, x_{-}\right\}$, where $x_{-}$is the lagged value of the fraction of the young living with the old that is a state variable due to the lagged externality, since these are sufficient statistics for wealth and prices.

\footnotetext{
${ }^{6}$ The relative sizes of the young and the old as well as the nature of the process for $\eta$ guarantee that there are not more young agents moving in with the old than the number of old households.
} 
Definition 1. A recursive equilibrium is a set of functions for capital, $K^{\prime}(s)$; consumption $\left\{c^{y A}(s), c^{y T}(s), c^{o}(s)\right\}$; hours worked $\left\{h^{y A}(s), h^{y T}(s), h^{o}(s)\right\}$; the threshold for staying at home $\eta^{*}(s)$; the fraction of young that move in with the old $x(s)$; and competitive factor prices $\{r(s), z(s)\}$, such that

1. The young maximize given the choice of the old. This includes the choices of consumption, hours worked when together, hours worked when alone, and household type.

2. The fraction of the young moving in with the old satisfies $x(s)=F\left(\eta^{*}(s) ; \lambda\right)$, and the marginal young are indifferent, i.e., $\eta^{*}(s)$ satisfies

$$
u\left[c^{y A}(s), h^{y A}(s)\right]=u\left[c^{y T}(s)+\zeta^{y}, h^{y A}(s), \eta^{*}(s)\right]
$$

3. The old maximize given the expected choices of the young, and when imposing the representative agent condition, their choices yield $\left\{K^{\prime}(s), c^{o}(s), h^{o}(s)\right\}$.

\section{Calibration}

Our main question is to ask how volatile are movements in hours that are driven by TFP shocks when it is recognized that people live in both stable and unstable households, and those in unstable households work less, are less productive, and move into the households of stable people in a countercyclical way.

One way to proceed would be to choose parameters so that the model generates the same volatility of hours of the young people, and the same volatility of household size, as in the data. We think that such a procedure would give a misleading answer because it would implicitly assume that all movements in hours are due to TFP shocks, whereas only a small fraction (around 5\% in a typical representative agent RBC model) of the volatility of hours of the old are due to TFP shocks. Instead we choose parameters so that shocks to TFP account for the same fraction of the variances of all types of hours worked and the variance of household size. Calibrating the model in this way requires that we target both first and 
second moments simultaneously. This means that the solution to the full stochastic model is required for calibration, rather than just its steady-state statistics.

\subsection{Baseline calibration}

Technology Technology is that of a standard RBC model: Cobb-Douglas in capital and labor with a shock to TFP. As stated above, hours of the young (i) command a lower wage (are less efficient than) hours of the old and (ii) are more volatile than hours of the old. These two facts imply that aggregate hours (the unweighted sum of all hours) are more volatile than the labor input (hours weighted by their efficiency). In our model the Solow residual - defined as $S R_{t}=\log Y_{t}-\alpha \log K_{t}-(1-\alpha) \log H_{t}$ - is not the same as the TFP shock. Consequently, the parameters that govern the stochastic process for TFP must be determined simultaneously with the other model parameters. This ensures that a univariate representation of the Solow residual from our model displays an autocorrelation of .9553 and a standard deviation for the innovation of $.688 \%$. The implied coefficients for the productivity shock in the baseline calibration are an autocorrelation of .9444 and a standard deviation of innovations of .621\%. Note that the total variance of the shock is smaller than that of the Solow residual. This is because hours worked is more volatile than the labor input, since the latter weighs the hours of the old more heavily, and these hours are less volatile than the hours of the young.

Table 3 shows the parameters and the targets that we use. The first set of parameters (in black) are those that can be set directly without solving the model. The second set of parameters (in blue) require the calculation of the steady-state to set its value. In this sense, finding the value requires solving a system of equations imposing the steady state targets. Finally, the third set of parameters (in red) require that we solve the whole model, where the system of equations includes second moments of time series.

Demographics In our baseline calibration we identify the unstable young as those aged below 30 , and the stable old as those aged 30 to 65 . Unless stated otherwise, the calibration and findings that we report in the main text refer to this definition.

Preferences of the old Table 4 displays the targets for the preferences of the old, under the baseline definition described above. The fraction of old agents is 0.684 , which is the average fraction of people aged 18 to 65 that are 30 and above, over the sample period in our CPS

data. Most of these people are married, generating an average household size of 1.8. The 
Table 3: Technological Parameters and Targets

\begin{tabular}{|c|c|c|c|c|}
\hline \multicolumn{2}{|c|}{ Parameter Description } & Target variable & Target & Parameter \\
\hline \multicolumn{5}{|c|}{ Parameters that can be set without solving the model } \\
\hline$\alpha$ & Capital Share & Capital Share & .67 & .67 \\
\hline$\varepsilon^{y}$ & Lab efficiency of young & Direct Measurement & .57 & .57 \\
\hline \multicolumn{5}{|c|}{ Parameters that require solving for the steady state } \\
\hline$\delta$ & Depreciation rate & $I / Y$ & .24 & .0263 \\
\hline \multicolumn{5}{|c|}{$\underline{\text { Parameters that require solving the full stochastic equilibrium }}$} \\
\hline$\rho$ & AR(1) prod shocks & Autocorr AR(1) RA Solow Res* & .9553 & .9444 \\
\hline$\sigma_{z}$ & St Dev productivity shocks & St Dev AR(1) RA Solow Res* & $.688 \%$ & $.621 \%$ \\
\hline
\end{tabular}

discount factor is $4 \%$ and is standard. Recall that the utility function of the old posed in equation (1) was separable between consumption and hours, with log utility for consumption and a constant Frisch elasticity for labor. Because of the presence of log utility, equilibrium allocations are not affected by the actual parameter values for economies of scale among the old. We report the OECD values for completeness.

For the Frisch elasticity of the old, we use a value that attempts to take into account both the extensive margin and the typical existence of a couple in an old household. Our baseline value of 0.72 is computed based on Heathcote, Storesletten, and Violante (2010). This number is very close to the value obtained by Chetty, Guren, Manoli, and Weber (2011a) of 0.82 in their meta-analysis of estimates for the Frisch elasticity using micro data. We also note that with one possible exception (the 1987 Iceland zero tax year studied by Bianchi, Gudmundsson, and Zoega (2001)), none of the studies analyzed by Chetty, Guren, Manoli, and Weber (2011a) or Chetty, Guren, Manoli, and Weber (2011b) are based on data that include the type of unstable marginal workers that we are emphasizing in this paper. We also perform a sensitivity analysis on the assumed Frisch elasticity of the old using values in $\{0.55,1.0\}$. For the disutility of work, we target a value of .5032 for mean hours worked, since this is the fraction of one adult's time endowment that is worked by the 1.8 adults in an old household. 
Table 4: Parameters of preferences of the old

\begin{tabular}{|c|c|c|c|c|}
\hline \multicolumn{2}{|c|}{ Parameter Description } & Target variable & Target & Parameter \\
\hline \multicolumn{5}{|c|}{ Parameters that can be set without solving the model } \\
\hline$\mu$ & Fraction of old & Measurement & 0.684 & 0.684 \\
\hline$\gamma$ & Old household size & Direct Measurement & 1.798 & 1.798 \\
\hline$\beta$ & Discount rate & Interest rate & 0.04 & 0.9902 \\
\hline$\zeta^{\circ o}$ & Ec of scale for old & OECD & 1.7 & 1.7 \\
\hline$\zeta^{\circ}$ & Additional Ec of scale & OECD & 0.5 & 0.5 \\
\hline$\nu^{o}$ & Frish elast of old & Measurement & 0.72 & 0.72 \\
\hline \multicolumn{5}{|c|}{ Parameters that require solving for the steady state } \\
\hline$\psi^{o}$ & Weight of hours of old & Hours in Old Hholds & 0.5032 & 4.4223 \\
\hline
\end{tabular}

Preferences of the young Table 5 displays the targets of the parameters concerning the young agents in the baseline economy. We target the following first moment statistics of the young: (i) hours worked if alone, (ii) hours worked if living with the old, and (iii) fraction of the young that live with the old.

We also target the following second moment statistics: (i) variance of hours worked if alone, (ii) variance of hours worked if living with the old, and (iii) variance of the fraction of the young that live with the old, all relative to the variance of hours of the old. This final target ensures our model does not feature more movement along the coresidence margin than is implied by the data. It is important to reiterate the fact that we target relative variances. Our goal is to measure the contribution of productivity shocks to the variance of hours. Our calibration strategy implies that the contribution of productivity shocks is the same for all of the components that contribute to move total hours: the hours of the old, the hours of the young living alone, the hours of the young living with the old, and the fraction of the young living with the old.

Table 5 also displays the seven parameters involved in the calibration: three standard parameters of the utility function (risk aversion, weight on hours, labor elasticity); two parameters governing the distribution of distaste for living with the old; one parameter for the economies of scale when living with the old; and one parameter governing the externality in living ar- 
Table 5: Parameters of preferences of the young

\begin{tabular}{lllcc}
\hline \hline \multicolumn{7}{c}{ Parameter Description } & Target variable & Target & Parameter \\
\hline \multicolumn{7}{c}{ All Parameters require solving the full stochastic equilibrium } \\
\hline \multicolumn{7}{c}{ Weight of hours of Young } & Hours of young together & 0.2105 & 6.1340 \\
$\psi^{y}$ & Shape par of Gamma dist & $\%$ of young with old & 50.23 & 0.7680 \\
$\lambda^{1}$ & Sisk Aversion of young & Hours of young alone & 0.2972 & 0.2385 \\
$\sigma^{y}$ & Risk & 0.4582 & 3.2026 \\
$\lambda^{2}$ & Scale par of Gamma dist & $\operatorname{Var}(x) / \operatorname{Var}\left(h^{\circ}\right)$ & 4.0131 & 1.0459 \\
$\nu^{y}$ & Frisch elasticity of Young & $\operatorname{Var}\left(h^{y T}\right) / \operatorname{Var}\left(h^{o}\right)$ & 1.7774 & 1.5445 \\
$\zeta^{y}$ & Ec of scale of Young & $\operatorname{Var}\left(h^{y A}\right) / \operatorname{Var}\left(h^{\circ}\right)$ & -0.4774 & 4.4100 \\
$\gamma_{2}$ & Curvature in externality & $\operatorname{Corr}(x, h)$ & & \\
\hline \hline
\end{tabular}

Variances are from logs and HP-filtered.

rangements. $^{7}$

The degree of risk aversion is particularly important. With log utility and no patience, hours are constant, irrespective of the wage rate. When risk aversion is greater than unity, hours move countercyclically, since the income effect of wage changes dominates the substitution effect. This means that in our calibrated economy, the risk aversion of the young is less than 1.

It is crucial that we allow the idiosyncratic shocks for the distaste of living with the old to be drawn from a flexible two-parameter distribution. We choose a Gamma distribution. If there were only one parameter, it would be pinned down by the mean fraction of the young living with the old. However, what matters for our question is the slope of the cumulative distribution function (CDF) at this value, since this is what determines the mass of young agents that are induced to change their living arrangements in response to small changes in the wage rate.

\footnotetext{
7 With the functional form that we have chosen all parameters affect all choices and, as a result, the calibration of the preference parameters of the young requires, that we solve for the stochastic equilibrium even though some of the targets are first moments.
} 


\subsection{Alternative calibrations}

In addition to our baseline calibration, we also consider various other model economies with slightly different calibration strategies. The parameters associated with the calibration of these alternative model economies can be found in Table 11 in the Appendix.

\subsubsection{Alternative definitions of the young}

In our baseline economy we identify the unstable young, somewhat arbitrarily, with individuals between 18 and 30 years old. We also consider three alternative definitions of the young. The first two of these definitions are based on equally arbitrary notions of who is young/unstable: (i) individuals who have never been married, and (ii) individuals who both have never been married and are between 18 and 30 years old. The third alternative definition of the unstable young is constructed not by choosing a particular demographic group, but by imposing that the implied movements in households per person relative to the variance of total hours of the old are the same in the model economy as in the data. The size of the young/unstable that achieves this target is higher than in the baseline economy: $39 \%$ compared with $32 \%$.

When the unstable young are defined by explicitly targeting a particular demographic group, it is possible to obtain direct measures of the volatility of hours of the young, both living together and living alone, of hours of the old, and of the fraction of the young living with the old, from the data. This is not the case for the third alternative definition of the young, since the members of the group are defined only implicitly. Given that we do not have direct measures of the variances of the relevant variables, we cannot use them as targets for calibration. Instead, we have used the relative variance targets from the baseline calibration when calibrating the economy with the implicit definition of the young.

\subsubsection{Alternative target for cyclicality of household size}

In our baseline calibration we target $\operatorname{Var}(x) / \operatorname{Var}\left(h^{\circ}\right)$ as a way of ensuring that our model features the correct degree of cyclicality in the living arrangements of the young. This choice of target implicitly assumes that the fraction of the observed cyclical variation in hours of old workers that is driven by TFP shocks is the same as the fraction of cyclical variation in the proportion of the young living with the old that is driven by TFP shocks. However, this may be overly conservative: it is feasible that TFP shocks account for a larger (or smaller) fraction 
of movements in household size than they do for hours worked.

To address this possibility, we also consider an alternative calibration strategy where we target directly the empirical counterpart of the counterfactual experiment that we are interested in: shutting down the margin of movements in $x$ over the business cycle. To do this we calculate how much smaller the variance of hours of the young would be in the data if $x$ were held constant at its mean value but $h^{y A}$ and $h^{y T}$ retained their empirical properties. Explicitly, we calculate a moment $M\left(h^{y A}, h^{y T}, x\right)$ given by

$$
\begin{aligned}
M & =1-\frac{\operatorname{Var}\left(\log \left[x_{S S} h^{y T}+\left(1-x_{S S}\right) h^{y A}\right]\right)}{\operatorname{Var}\left(\log \left[x h^{y T}+(1-x) h^{y A}\right]\right)} \\
& =1-\frac{\operatorname{Var}\left(\log \left[x_{S S} h^{y T}+\left(1-x_{S S}\right) h^{y A}\right]\right)}{\operatorname{Var}\left(\log h^{y}\right)} .
\end{aligned}
$$

$M$ compares the volatility of hours of the young with the volatility of a counterfactual series for hours that holds $x$ fixed at its steady-state value. It thus provides a direct measurement of how much movement there is in $x$ over the business cycle: the target value is 0.11 . In this calibration we substitute only one calibration target, yet all nine parameters in Table 5 change, as well as the two parameters that determine the productivity shock process.

\subsubsection{Economies without the externality}

Our baseline economy includes a highly unusual, and perhaps controversial, feature: an externality in the utility cost for the young to live with the old. So that we can explain why it is important to include such an externality in the baseline model, we also consider two versions of the model without the externality, in which we drop the final term in (4). Since there is one less parameter, in the first alternative economy, we exclude one moment from the set of calibration targets: the correlation between hours worked and coresidence. This is the moment that pins down the extent of the externality in the baseline model. In the second alternative economy we introduce an iid shock to the shape parameter of the Gamma distribution, $\lambda_{t}^{1}=\lambda^{1}+\epsilon_{t}$, where $\epsilon_{t} \sim N\left(0, \sigma_{x}\right)$. In this latter economy, we are able to target the correlation between hours worked and coresidence by choosing the variance of the iid shock, $\sigma_{x}$. In Section 6.3 we discuss the implications of these alternative economies. 
Table 6: Second Moments of the Data, Standard Representative Agent and Baseline Economy

\begin{tabular}{|c|c|c|c|c|c|}
\hline & \multirow[t]{2}{*}{ Data } & \multicolumn{2}{|c|}{ Representative Agent } & \multicolumn{2}{|r|}{ Baseline } \\
\hline & & Value & $\%$ Accounted for & Value & $\%$ Accounted for \\
\hline $\operatorname{var}(h)$ & 2.03 & .0908 & $4.5 \%$ & .1547 & $7.6 \%$ \\
\hline $\operatorname{var}\left(h^{y}\right)$ & 4.16 & & & .3121 & $7.5 \%$ \\
\hline $\operatorname{var}\left(h^{o}\right)$ & 1.52 & & & .1100 & $7.2 \%$ \\
\hline $\operatorname{var}\left(h^{y A}\right)$ & 2.70 & & & .1956 & $7.2 \%$ \\
\hline $\operatorname{var}\left(h^{y T}\right)$ & 6.10 & & & .4416 & $7.2 \%$ \\
\hline $\operatorname{var}(x)$ & 0.70 & & & .0504 & $7.2 \%$ \\
\hline $\operatorname{cor}(x, h)$ & -0.48 & & & -.4774 & $100 \%$ \\
\hline $\operatorname{var}(S R)$ & 3.19 & 3.19 & $100 \%$ & 3.19 & $100 \%$ \\
\hline $\operatorname{autcor}(S R)$ & 0.94 & 0.94 & $100 \%$ & 0.94 & $100 \%$ \\
\hline \multicolumn{6}{|c|}{ Contribution of households per person + covariance } \\
\hline & $15.2 \%$ & $0.0 \%$ & & $13.3 \%$ & $87.2 \%$ \\
\hline
\end{tabular}

\section{Findings}

\subsection{The cyclical volatility of hours worked}

Table 6 displays our main findings with respect to the cyclicality of hours worked. The first column shows the relevant second moments of the data, starting with the cyclical volatility of total hours. The remaining moments are the variances of hours of the young, the old, the young living alone, and the young living with the old, as well as the variance of the fraction living alone. We also report the correlation between the fraction of the young living with the old and total hours, and the moments of the Solow residual. As discussed in Section 2, the old have a lower volatility than the young, and the volatility of the young is far higher when they live inside an old household than when they live alone.

The second and third columns report the volatility of hours in a standard representative agent real business cycle model with a Frisch elasticity of .72, and the ratio of the model variances to the data. The volatility of hours in the standard model is very small: just $4.5 \%$ of that in 
the data.

The final two columns report the analogous findings for the baseline economy. Recall that our calibration strategy imposed that productivity shocks should account for the same fraction of the total variance of all components of hours worked, which turns out to be $7.2 \%$. However, because in the model these components are all slightly more correlated than in the data, the overall contribution of total hours is measured to be $7.6 \%$. This is still very low by absolute standards but is $70.3 \%$ larger than the representative agent model despite the fact that the Frisch elasticity of the stable agents is the same in both economies (0.72).

The final row of Table 6, displays the contribution of households per person to the variance of hours worked (including the associated covariance) in the model and the data. The model generates only $87 \%$ of this contribution that is in the data (13.3\% vs. $15.2 \%)$. This suggests that for cyclical purposes, our definition of the young is too narrow, i.e., there is an insufficient role for variation in family size in the baseline model economy. We explore this issue in more detail in Section 6.3.

\subsection{Decomposition of hours volatility}

There are three reasons why total hours are more volatile in our economy than in the representative agent economy: (i) the presence of young agents who are more volatile than old agents; (ii) changes in relative prices that induce further changes in behavior; (iii) the ability and willingness of the young to move in and out of households. We now decompose the difference between our baseline economy and the representative agent economy into these three effects. To do this, we build up to the baseline model, starting from the standard representative agent model, adding one element at a time.

(i) The young are more volatile than the old. The mere presence of the volatile young in the model increases the variances of total hours. The young, whether living alone or living together with the old, have more volatile hours than the old do. This, on its own, increases total hours volatility. To quantify the effect of this channel, we construct an economy with the relative prices of the representative agent economy and adding two groups of young agents, a constant fraction of whom live with the old, and the rest of whom live alone. In this economy there are no movements in the coresidence margin. This allows us to isolate the effect of the presence of the young. 
Table 7: Decomposition of hours volatility

\begin{tabular}{|c|c|c|c|c|c|c|}
\hline & \multicolumn{3}{|c|}{ Contribution } & \multirow[b]{2}{*}{$\operatorname{var}\left(h^{y}\right)$} & \multirow[b]{2}{*}{$\operatorname{var}(x)$} & \multirow{2}{*}{$\begin{array}{r}\text { Implied } \\
\text { Frisch }\end{array}$} \\
\hline & $\operatorname{var}(h)$ & $\%$ & $\operatorname{var}\left(h^{\circ}\right)$ & & & \\
\hline Representative agent model & .0908 & & 0908 & & & .7200 \\
\hline + Presence of the young & 1362 & 71.0 & .0908 & .2956 & & .9519 \\
\hline + Price changes & 1499 & 21.5 & 1087 & .2878 & & 1.0203 \\
\hline + Movements in household size & 1546 & 7.5 & 1100 & .3121 & .0504 & 1.0441 \\
\hline
\end{tabular}

The second row of Table 7 reports the results. Adding young agents to the economy, some of whom live with the old and some of whom live alone, increases the variance of total hours by $50 \%$ relative to the representative agent economy (0.1362 vs. 0.0908). This accounts for $71 \%$ of the total increase in our baseline economy and turns out to be the most important margin among the three channels.

(ii) Changes in relative prices. The third row in Table 7 reports the results in which prices are allowed to adjust endogenously, in addition to the presence of the two groups of the young, a constant fraction that lives alone and the rest that live with older households. In this economy, prices adjust endogenously. The variance of total hours is increased by a further $15.1 \%$ ( 0.1499 vs 0.908 ), which reflects $22.7 \%$ of an increase relative to the representative agent economy.

The source of this increase in hours volatility is particularly informative. The increase from this channel is due to an increase in the hours volatility of the old. This is offset by a decrease in the hours volatility of the young living at home and of the young living alone. The presence of the young whose hours volatility is higher than that of the old affects relative prices in a specific way: they dampen movements (variance) in wages (.484 vs. .497), but exacerbate those of the rate of return that becomes more volatile (15.46 vs. 13.87). The old, because they have intertemporal concerns, respond more to changes in the rate of return than to changes in wages. Hence, their hours are more volatile in the baseline economy than in the representative agent economy. The young, on the other hand, do not have any intertemporal concerns. Hence, they are unaffected by changes in the rate of return and only respond to wages. But since wages are less volatile in the baseline economy, so too are the hours of the young. This channel accounts for $21.5 \%$ of the increase in the variance of hours. 
(iii) Movements in and out of households: The coresidence channel. In addition to the presence of the young, movements in the fraction of the young living with the old over the business cycle affect the variance of total hours. During bad times, more young agents move in with old agents. This reduces the average hours of the young in bad times, since they work less while living with the old, which increases the variance of total hours.

To isolate the effect of this channel, we compare the previous economy reported in the third row of Table 7 with the properties of the baseline economy reported in the last row of Table 7 results. The effect of allowing for movements of people across households is to increase the variance of hours by a further $5.2 \%$, relative to the representative agent model (0.1546 vs. 0.0908). This increase reflects $7.5 \%$ of the total increase in our baseline economy. We can further decompose the $7.5 \%$ contribution of the corresidence channel into the direct effect that results from allowing the corresidence channel using the prices of the previous economy where there was no coresidence channel $(6.4 \%$ out of $7.5 \%)$ and the indirect effect induced by the further change in prices motivated by the coresidence channel (1.1\% of the $7.5 \%)$.

\subsection{Findings from alternative calibrations}

Alternative definitions of the young Recall that we also consider three alternative definitions for the young agents in our economy: (i) never-married individuals; (ii) never-married individuals under 30; and (iii) an implicit definition that calibrates the fraction of the young so that the ratio of the variation of households per person plus associated covariance terms to the variance of hours worked is the same in the model and the data.

The findings are reported in Table 8. Unsurprisingly, the volatility of hours is slightly smaller for the narrow definitions of the young. Interestingly, for the narrowest definition (nevermarried individuals under 30) we see that the variance of the hours of the young is the largest of all the groups (recall that we target the relative variance of the hours of that particular group), but the size of the group is too small for this to have a large impact on the volatility of total hours worked. Overall, our basic findings are not affected by defining the young as different explicit demographic groups: we find a $54 \%$ (42\%) increase in total hours volatility when the young are defined as never-married individuals (never-married individuals under 30), compared with an increase of $70 \%$ in our baseline calibration, where the young are defined as individuals under 30 .

The economy with an implicit definition of the young, calibrated so that the contribution of 
Table 8: Second Moments of Main Variables for Alternative Calibrations

\begin{tabular}{|c|c|c|c|c|c|c|}
\hline & $\operatorname{var}(h)$ & $\operatorname{var}\left(h^{o}\right)$ & $\operatorname{var}\left(h^{y}\right)$ & $\operatorname{var}(x)$ & $\begin{array}{c}\text { Contr of } \mathrm{HH} \\
\text { per pers }+\mathrm{cov}\end{array}$ & $\operatorname{cor}(x, h)$ \\
\hline Representative agent model & .0908 & .0908 & - & - & - & - \\
\hline Baseline economy & .1547 & .1100 & .3121 & .0504 & 13.3 & -.48 \\
\hline \multicolumn{7}{|l|}{ Alternative definitions of young } \\
\hline Never married & .1399 & .1056 & .3054 & .0426 & 7.3 & -.33 \\
\hline Never married, 18-30 & .1290 & .1007 & .3613 & .0270 & 7.2 & -.37 \\
\hline Implicit definition & .1776 & .1168 & .3302 & .0535 & 15.2 & -.48 \\
\hline \multicolumn{7}{|l|}{ Alternative calibrations } \\
\hline Target for $\operatorname{var}(x)(M)$ & .1567 & .1104 & .3228 & .0937 & 16.5 & -.48 \\
\hline Economy without externality & .1587 & .1096 & .3274 & .0502 & 30.0 & -.99 \\
\hline No externality $+\lambda^{1}$ iid & .1537 & .1093 & .3046 & .0501 & 13.3 & -.48 \\
\hline
\end{tabular}

The implicit definition of the young is chosen so that the size of the young generates a contribution of the variance of households per person to total hours volatility that is the same as in the data. The economy with the alternative target for $\operatorname{var}(x)$ matches the contribution of the movements in household composition to the volatility of young hours, rather than the relative variance of the fraction of the young living with the old. See Section 5.2.2 for full details. 
changes in households per person to the variance of aggregate hours is the same in the data $(15.2 \%)$, generates a much larger volatility of hours, 0.178 . One might argue that the correct value for the fraction of young agents is somewhere between the values in the baseline economy and this economy. The baseline economy generates too small a contribution of households per person to the total variance of hours $(13.3 \%$ vs. $15.2 \%)$. However, the economy with the implicit definition of the young has more young agents, yet targets the relative volatility of a smaller group that may be more volatile than the implicitly defined group.

Alternative target for cyclicality of household size Table 8 also reports findings for the economy that targets the $M$ statistics defined in Section 5.2.2. Recall that $M$ measures the contribution of the variation in the fraction of the young living with the old to the volatility of hours of the young. As discussed in Section 5.2.2, this economy does not impose that the contribution of TFP shocks to movements in household composition is the same as the contribution of TFP shocks to movements in hours. Instead, it imposes that the fraction of the hours volatility in the young that is accounted for by variation in coresidence is the same in the model and the data. This economy yields a variance of hours (0.157) slightly higher than in the baseline (.155), despite having a total contribution of the movements of households per person to total hours $(16.5 \%)$ that is larger than in the baseline $(13.3 \%)$ and indeed that in the data $(15.2 \%)$. It does so by posing a much larger, almost double, variation of the fraction of the young living alone. The reason why the economy with the implicit definition of the young previous economy has a much larger total volatility of hours is that the implied size of the young is larger than in the economy that targets $M$, even though in the latter the living arrangements are more volatile.

Economies without externalities The first of the two economies without the externality in the disutility of living with the old generates a somewhat larger volatility of hours than in the baseline economy (.159), despite the fact that it targets the same relative variances of all variables as in the baseline. This is because without the externality, the correlation between coresidence and hours is not included as a calibration target. As a a result, the economy without the externality implies a correlation between the fraction of the young living with the old and total hours that is far too strong (-.99), compared with the data (-.48). With such strong comovement of living arrangements and hours, the contribution of movements in households per person to the total variance of hours is $30 \%$, which is twice the contribution in the data. The reason that we include the externality in the baseline model is that it serves 
to lower this correlation to a level that is consistent with the data.

The second of the two economies without the externality is intended to illustrate that the externality is not essential for generating the right correlation between coresidence and hours. To do this, we add an iid shock to the shape parameter of Gamma distribution $\lambda^{1}$, and choose its variance to target this correlation. This economy, shown in the final row of Table 8 displays very similar features to the baseline economy. The variance of total hours is .1537, and the contribution of the variance of households per person to the total variance of hours is the same as in the baseline. Thus, one may ask why we did not choose to use this economy as our baseline? The answer is that this economy features two aggregate shocks, both of which have an effect on hours and coresidence movements, while the standard representative agent model has only one shock. This would make it difficult to understand whether the additional hours volatility in the model with coresidence is due to the mechanisms described above, or simply due to the presence of an additional aggregate shock.

\section{Implications for the calibration of representative agent models}

The aim of this paper is in part to show that the macro labor elasticity is indeed different from the micro elasticity, while remaining scrupulously respectful of measurements of the micro elasticity that are based on direct empirical evidence. Consequently, we now ask the question of how much higher is the macro elasticity when we are explicit about both the existence of young people and the existence of movements in household size. To answer this question, we calibrate a standard representative agent business cycle model by choosing the Frisch elasticity so that the representative agent model generates the same volatility of total hours as the model economies that we have studied in this paper.

Table 9 reports these findings. For our baseline definition of the young, we find that the implied macro Frisch elasticity is 1.04. Since the elasticity of the old in our baseline economy was 0.72 , our findings suggest an increase in the Frisch elasticity of around $45 \%$. The highest implied macro elasticity results when the economy is calibrated to replicate the movements in household composition: 1.16, which reflects an increase of $61 \%$. For the stricter definitions of the young, this percentage increase is between $27 \%$ and $35 \%$. In our alternative calibrations

that match the contribution of movements in household composition to the volatility of young hours and in the economy with no externality, we get results that are very similar to the baseline: a macro elasticity that is between $45 \%$ and $50 \%$ higher than the micro elasticity. 
Table 9: Macro elasticity comparable to a micro elasticity of 0.72

\begin{tabular}{lcc}
\hline \hline & $\begin{array}{c}\text { Implied Frisch } \\
\text { in RA RBC }\end{array}$ & $\begin{array}{c}\text { Proportional } \\
\text { Increase }\end{array}$ \\
\hline Baseline economy & 1.044 & $45 \%$ \\
Alternative definitions of young & & \\
\hline Never married & 0.971 & $35 \%$ \\
Never married, 18-30 & 0.916 & $27 \%$ \\
Implicit definition & 1.158 & $61 \%$ \\
Alternative calibrations & & \\
Target for var $(x)$ & 1.054 & $46 \%$ \\
Economy without externality & 1.064 & $48 \%$ \\
No externality $+\lambda^{1}$ iid & 1.039 & $44 \%$ \\
& & \\
\hline \hline
\end{tabular}

The implicit definition of the young is chosen so that the size of the young generates a contribution of the variance of households per person to total hours volatility that is the same as in the data. The economy with the alternative target for $\operatorname{var}(x)$ matches the contribution of the movements in household composition to the volatility in young hours, rather than the relative variance of the fraction of the young living with the old. See Section 5.2.2 for full details. 
Table 10: Macro elasticity for alternative micro elasticities

\begin{tabular}{lcc}
\hline \hline & Implied Frisch & $\begin{array}{c}\text { Proportional } \\
\text { Increase }\end{array}$ \\
\hline & & \\
$\nu=0.72$ (baseline) & 1.0442 & $45 \%$ \\
$\nu=0.55$ & 0.7691 & $40 \%$ \\
$\nu=1.0$ & 1.5463 & $55 \%$ \\
\hline
\end{tabular}

Alternative assumptions for micro Frisch elasticity A concern that we have is whether the increase in the Frisch elasticity when moving from a representative agent economy to an economy with unstable agents is affected by the level of the actual micro Frisch elasticity. ${ }^{8}$ The reason for this concern is the non-linearity of the underlying model. To explore this issue, we replicated the analysis above for an economy where all the targets are the same as in the baseline, except for the Frisch elasticity of the stable old agents. We consider values of .55 and 1.0. Table 10 reports the representative agent counterpart of our economies with young agents. We find that the level matters to some extent: the higher the initial value of the Frisch elasticity, the higher the extra kick that results from explicitly modeling the unstable young agents. While for the baseline choice of a Frisch elasticity equal to .72, we obtain an increase of $45 \%$, the implied increase when we start with a Frisch elasticity of $1.00(0.55)$ is $55 \%(40 \%)$.

\section{Conclusions}

In this paper we have explored the role of countercyclical movements in household size for business cycles. We started by providing evidence on this often suspected, but not documented, feature of how people bear bad times. We find that cyclical movements in household size are large: changes in the average number of households per person account for $15 \%$ of the cyclical variation in hours worked per person. A large part of these changes in household composition is due to young, or unstable, individuals moving in and out of the homes of older,

\footnotetext{
${ }^{8}$ Chetty, Guren, Manoli, and Weber (2011a) and Chetty, Guren, Manoli, and Weber (2011b) conduct a meta analysis of micro estimates of the Frisch elasticity. Of all the studies they examine, only one could be argued to include the type of individuals with unstable living arrangements that we focus on in this paper: this is the study of Iceland's temporary tax holiday by Bianchi, Gudmundsson, and Zoega (2001). The remaining studies should be interpreted as estimates of the Frisch elasticity for stable or old individuals.
} 
stable individuals.

We then posed a model with both stable and unstable individuals where household composition is chosen optimally by the unstable agents in the model. Our model is embedded in a growth model that is suitable for business cycle analysis. We used the model to reassess the importance of TFP shocks for hours volatility.

Our findings for the volatility of hours can be summarized as follows. Although TFP shocks in a baseline representative agent economy account for a very small fraction of the observed volatility of hours, this fraction increases by around $70 \%$ when (i) the existence of young people, some of whom live with the old, is taken into account; and (ii) it is recognized that they move in and out of older households in a cyclical manner. We decomposed the reasons for the increase in hours volatility. About $71 \%$ is due to the existence of young, unstable agents with a high labor elasticity, $7.5 \%$ to movements in and out of households, and $21.5 \%$ to changes in hours of the old that arise because of changes in relative prices induced by the behavior of the young. Together, this increases what we call the macro elasticity by around $50 \%$ over the micro elasticity: when the Frisch elasticity for the stable, old individuals in our model is 0.72 , a representative agent model would require a Frisch elasticity of 1.04 to generate the same total volatility of hours. Our findings are very robust to details of the calibration.

We conclude that macroeconomists now have a powerful argument to claim that the macro labor elasticity is larger than that yielded by micro studies that are based on stable households. Our work suggests that household composition choice should become a major part of the large class of models in which agents are subject to uninsurable idiosyncratic shocks. 


\section{References}

Bianchi, M., B. R. Gudmundsson, and G. Zoega (2001): "Iceland's Natural Experiment in Supply-Side Economics," American Economic Review, 91(5), 1564-1579.

Chetty, R., A. Guren, D. S. Manoli, and A. Weber (2011a): "Are Micro and Macro Labor Supply Elasticities Consistent? A Review of Evidence on the Intensive and Extensive Margins," in American Economic Review: Paper and Proceedings, vol. 101(3), pp. 471-475.

(2011b): "Does Indivisible Labor Explain the Difference Between Micro and Macro Elasticities? A Meta-Analysis of Extensive Margin Elasticities," NBER Working Papers, 16729.

Clark, K. B., and L. H. Summers (1981): "Demographic Differences in Cyclical Employment Variation," Journal of Human Resources, 16, 61-79.

Gomme, P., R. Rogerson, P. Rupert, and R. Wright (2005): "The Business Cycle and the Life Cycle," in NBER Macroeconomics Annual 2004, ed. by M. Gertler, and K. Rogoff, vol. 19, pp. 415-592. MIT Press.

Heathcote, J., K. Storesletten, and G. L. Violante (2010): "The Macroeconomic Implications of Rising Wage Inequality in the United States," Journal of Political Economy, 118(4), 681-722.

Jaimovich, N., S. Pruitt, and H. E. Siu (2009): "The Demand for Youth: Implications for the Hours Volatility Puzzle," NBER Working Papers, 14697.

Jaimovich, N., And H. E. Siu (2009): "The Young, the Old, and the Restless: Demographics and Business Cycle Volatility," American Economic Review, 99(3), 804-826.

Kaplan, G. (2010): "Moving Back Home: Insurance against Labor Market Risk," Staff Report, (449), Federal Reserve Bank of Minneapolis.

Kydland, F. E. (1984): "Labor-Force Heterogeneity and the Business Cycle," CarnegieRochester Conference Series on Public Policy, 21, 173-209.

Luungqvist, L., And T. Sargent (2011): "A Labor Supply Elasticity Accord?," American Economic Review, 101(3), 487-491. 
Mulligan, C., and Y. Rubinstein (2003): "Household vs Personal Accounts of the U.S. Labor Market, 1967-97," Working Paper, Foerder Institute of Economic Research.

Prescott, E. C. (2006): "Nobel Lecture: the Transformation of Macroeconomic Policy and Research," Journal of Political Economy, 114(2), 203-235.

Ríos-Rull, J.-V. (1992): "Business Cycle Behavior of Life-Cycle Economies with Incomplete Markets," Cuadernos Economicos de ICE, 51(2), 173-96.

- (1993): "Working in the Market, Working at Home and the Acquisition of Skills: A General-Equilibrium Approach," American Economic Review, 83(4), 893-907.

(1996): "Life Cycle Economies and Aggregate Fluctuations," The Review of Economic Studies, 63(3), 465-490.

\section{Appendix}

\section{A Other Data of Interest}




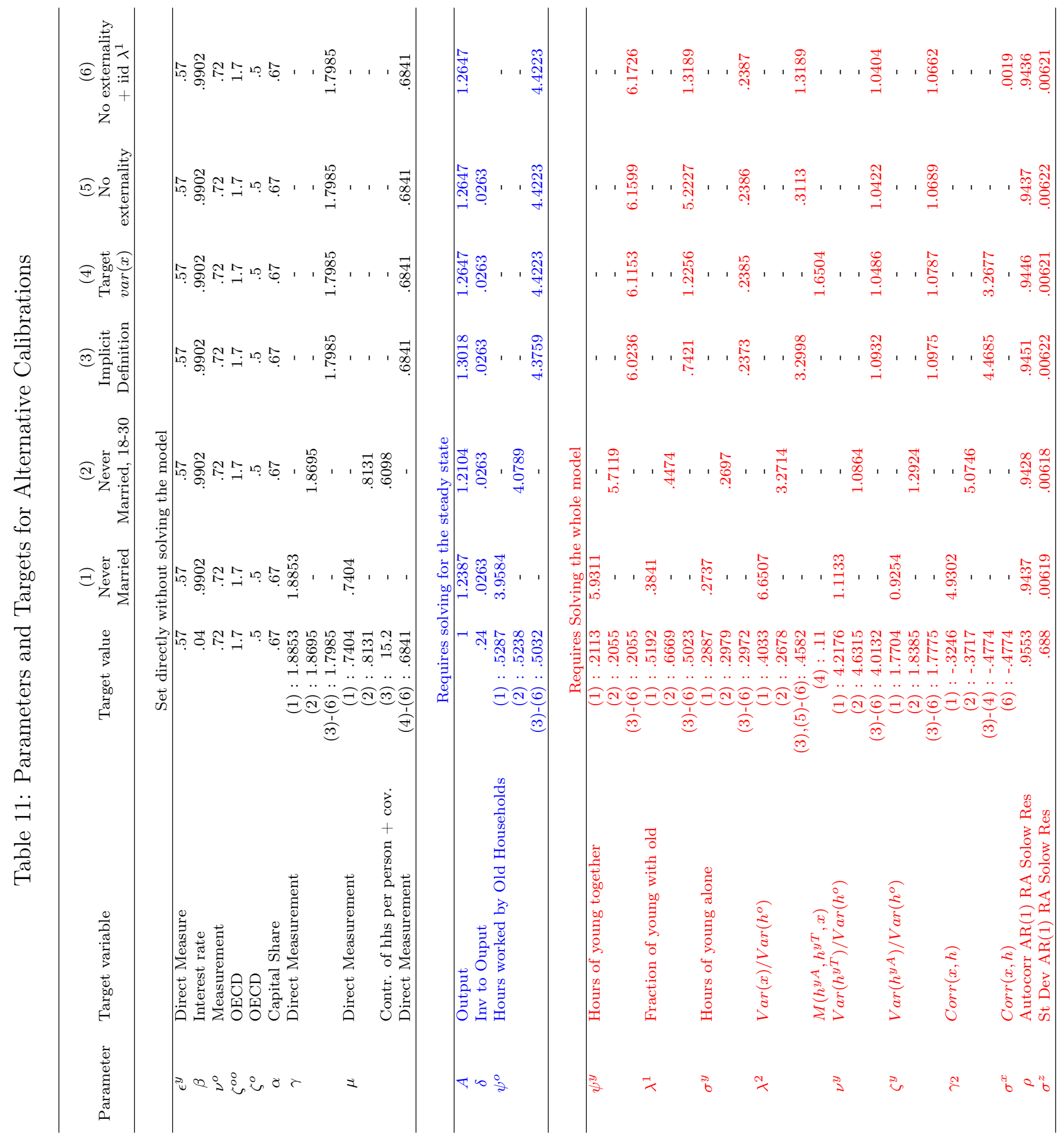

